\title{
HUBUNGAN ANTARA ERGONOMI KERJA TERHADAP TIMBULNYA GANGGUAN KESEHATAN AKIBAT KERJA PADA PEKERJA DI PG KREMBOONG SIDOARJO
}

\author{
Dwi Purwanti \\ Inst Puskesmas Pancoran Mas - Depok Jawa Barat
}

\begin{abstract}
ABSTRAK
HUBUNGAN ANTARA ERGONOMI KERJA TERHADAP TIMBULNYA GANGGUAN KESEHATAN AKIBAT KERJA PADA PEKERJA DI PG KREMBOONG SIDOARJO. Penelitian tentang ergonomi kerja dan timbulnya gangguan kesehatan akibat kerja masih sedikit terutama pada pabrik gula ini, ergonomi kerja hanya diketahui istilahnya saja tetapi penerapannya belum maximal dan jarang sekali terdapat penelitian gangguan kesehatan akibat kerja. Penelitian ini bertujuan untuk mengetahui hubungan ergonomi kerja terhadap timbulnya gangguan kesehatan akibat kerja pada pekerja PG KREMBOONG. Metode penelitian yang digunakan adalah analitik deskripsi observasional dengan pendekatan secara cross sectional. Populasi adalah karyawan yang bekerja di PG KREMBOONG dengan 60 sampel. Data didapatkan melalui data primer dan kuesioner yang dianalisa dengan uji validitas, reliabilitas dan uji chi square. Adanya hubungan ergonomi kerja terhadap gangguan kesehatan akibat kerja diuji menggunakan product moment corelations. Hasil penelitian menunjukkan terdapat hubungan yang signifikan antara ergonomi kerja terhadap timbulnya gangguan kesehatan akibat kerja dengan nilai $\mathrm{R}$ sebesar 0,608. Gangguan kesehatan akibat kerja berupa: nyeri pinggang, nyeri lutut, pusing. Faktor yang mempengaruhi ergonomi kerja : posisi kerja dan perubahan posisi kerja. Kesimpulan adalah terdapat hubungan antara ergonomi kerja terhadap timbulnya gangguan kesehatan akibat kerja.
\end{abstract}

\begin{abstract}
THE RELATIONSHIP AMONG ERGONOMIC WORK TOWARD THE AROUSE OF HEALTH DISTURBANCE CAUSED WORK IN PG KREMBOONG SIDOARJO. The research about ergonomic work and the arouse of health disturbance caused of work effect is a rare, especially in sugar factory. The word ergonomic work has known as the meaning term only. Meanwbile, the application is bad. It's rare to find research discuss health disturbance caused of work. The aims of research to know the relationship among ergonomic work toward the arouse of health disturbance caused work in PG KREMBOONG. The method of research is observational descriptive analytic with approach on cross sectional. Population are worker who work in PG KREMBOONG with 60 sampel. Data gathering from primer and questioner data. That is analysis by validity, realibility and chi square test. The existence of relationship among ergonomic work toward health disturbance caused of work has tested by using product moment correlations. The result of the research shows, there is significant relationship between ergonomic work toward bealth disturbance caused of work with coefisien $\mathrm{R}=0,608$. The effect are: low back pain, knee pain. The factors that influence ergonomic work: work, position and diversion of work position. The conclusion: there is relationship among ergonomic work toward the arouse of health disturbance caused of work.
\end{abstract}

Key word : Ergonomic work, The disturbance health, PG KREMBOONG, Sidoarjo.

\section{PENDAHULUAN}

Kasus gangguan kesehatan akibat kerja jarang dideteksi dan sulit dimonitor. Apabila kondisi ini kurang mendapat perhatian maka akan berdampak pada menurunnya sumber daya manusia. "Jika sudah begitu, perusahaan yang juga harus menanggung akibatnya, baik dari pembiayaan pengobatan maupun turunnya kinerja pegawainya."

Ilmu ergonomi di Indonesia telah mulai dikenal sejak dulu, namun sampai saat ini penerapannya masih jauh dari harapan. Banyak faktor yang menyebabkan kurang membudayanya penerapan ergonomi, diantaranya disebabkan karena masih kurangnya pengetahuan tentang ergonomi sehingga sosialisasi pembudayaan penerapan ergonomi dimasyarakat terhambat (Tarwaka dkk, 2004).
Data dari International Labor Organization (ILO) pada peralihan milenium kedua dan ketiga tersebut mengungkap terjadinya 250 juta kecelakaan yang terjadi di industri-industri di dunia yang menyebabkan 300.000 kematian. Tambahan pula, setiap tahun terjadi 160 juta penyakit akibat hubungan kerja yang baru.

WHO menentukan ada 150 penyakit akibat kerja, akan tetapi Indonesia hanya menetapkan 105 penyakit. Kepala Pusat Kesehatan Kerja Departemen Kesehatan Erna Tresnaningsih mengatakan, data tentang penyakit akibat kerja tidak pernah ada. Survalians untuk penyakit akibat kerja pun belum ada. Data kesehatan akibat kerja sangat penting karena bisa diketahui penyakit apa saja yang muncul akibat kerja (DepKes,2007). 
Di Indonesia penelitian yang mengungkap ergonomi dan timbulnya gangguan kesehatan akibat kerja masih sedikit. Pada pabrik gula ini, ergonomi kerja hanya diketahui istilahnya saja tetapi penerapannya belum maksimal dan jarang sekali terdapat penelitian gangguan kesehatan akibat kerja. Pada pabrik gula ini didapatkan data dari balai pengobatan yang menjelaskan gangguan kesehatan yang terbanyak adalah hipertensi $(2,14 \%)$, penyakit sistem otot $(1,71 \%)$, ISPA $(1,49 \%)$. Berdasarkan hal tersebut peneliti tertarik untuk meneliti gangguan kesehatan apa saja yang berhubungan dengan ergonomi kerja pada lingkungan industri khususnya dipabrik gula ini.

\section{METODE}

enelitian ini menggunakan metode observasional deskriptif analitik dengan studi cross sectional untuk menilai hubungan antara ergonomi kerja terhadap gangguan kesehatan akibat kerja. Penelitian ini dilakukan di Pabrik Gula KREMBOONG, Kecamatan Krembung Kabupaten Sidoarjo. Adapun waktu penelitiannya dilakukan pada bulan Oktober - Desember 2007.

Populasi dari penelitian ini adalah karyawan yang bekerja di PG KREMBOONG Sidoarjo. Objek penelitian ini adalah karyawan yang bekerja dibagian tanaman, AKU (Administrasi Keuangan Umum), instalasi. Kemudian sampel diambil menggunakan cara stratified random sampling, yang mana memenuhi karakteristik sampel penelitian sebanyak 156 orang sehingga didapatkan sampel sebanyak 60 dengan menggunakan rumus Slovin. Karakteristik sampel penelitiannya adalah pekerja usia 20-44 tahun (usia terbanyak yang menderita gangguan kesehatan), semua jenis kelamin, bekerja minimal 5 tahun, dan menggunakan alat kerja dan berada di lingkungan kerja.

\begin{tabular}{|c|c|c|c|c|}
\hline $\begin{array}{c}\mathrm{N} \\
\mathrm{O}\end{array}$ & Variabel & $\begin{array}{c}\text { Bagian } \\
\text { Instalasi } \\
(\%)\end{array}$ & $\begin{array}{c}\text { Bagian } \\
\text { AKU }(\%)\end{array}$ & $\begin{array}{c}\text { Bagian } \\
\text { Tanaman } \\
(\%) \\
\end{array}$ \\
\hline \multirow[t]{4}{*}{1} & Cara kerja : Posisi saat kerja & & & \\
\hline & Posisi duduk & 29 & 100 & 60 \\
\hline & Posisi berdiri & 45 & 0 & 40 \\
\hline & $\begin{array}{l}\text { Posisi selain duduk dan } \\
\text { berdiri }\end{array}$ & 26 & 0 & 0 \\
\hline \multirow[t]{5}{*}{2} & Cara kerja : Lama posisi kerja & & & \\
\hline & $5 \mathrm{jam}$ & 7 & 49 & 40 \\
\hline & $6 \mathrm{jam}$ & 0 & 38 & 0 \\
\hline & 7 jam & 26 & 13 & 20 \\
\hline & 8 jam & 67 & 0 & 40 \\
\hline \multirow[t]{3}{*}{3} & $\begin{array}{l}\text { Cara kerja : Perubahan posisi } \\
\text { saat bekerja }\end{array}$ & & & \\
\hline & Ada & 29 & 25 & 50 \\
\hline & Tidak ada & 71 & 75 & 50 \\
\hline \multirow[t]{5}{*}{4} & $\begin{array}{l}\text { Alat kerja : Atribut atau alat } \\
\text { pengaman yang dipakai saat } \\
\text { bekerja }\end{array}$ & & & \\
\hline & Atribut baju kerja & 33 & 100 & 100 \\
\hline & Masker & 60 & 0 & 0 \\
\hline & Penutup rambut & 7 & 0 & 0 \\
\hline & Sarung tangan & 0 & 0 & 0 \\
\hline \multirow[t]{4}{*}{5} & Lingkungan kerja & & & \\
\hline & Baik & 160,64 & 39,81 & 47.78 \\
\hline & Cukup & 54,22 & 9,19 & 13,22 \\
\hline & Kurang & 31,14 & 0 & 0 \\
\hline
\end{tabular}

Data penelitian diambil dari wawancara dan pengisian angket oleh responden, serta dokumen perusahaan mengenai respoden/karyawan dan berkaitan dengan instansi yang terkait. Data yang diperoleh melalui kuisioner akan diuji validitas dan realibilitas kemudian dibagikan kepada responden. Data yang diperoleh melalui kuisioner akan diuji validitas dan realibilitas kemudian dibagikan kepada responden. Uji validitas dilakukan untuk mengetahui apakah kuisioner yang kita susun tersebut mampu mengukur apa yang hendak kita ukur, maka perlu diuji dengan uji korelasi antara skor (nilai) tiap-tiap item (pertanyaan) dengan skor total kuisioner tersebut. Bila semua pertanyaan itu mempunyai korelasi yang bermakna (construct validity) sedangkan uji realibilitas digunakan untuk menunjukkan sejauh mana suatu alat pengukur dapat dipercaya atau dapat diandalkan. Hal ini berarti menunjukkan sejauh mana hasil pengukuran itu tetap konsisten atau tetap asas bila dilakukan pengukuran dua kali atau lebih terhadap gejala yang sama, dengan menggunakan alat ukur yang sama. Analisa data pada penelitian ini menggunakan uji korelasi yang dilakukan untuk mengetahui ada tidaknya hubungan antara ergonomi kerja dengan gangguan kesehatan akibat kerja. Dari hasil kuisioner akan ditabulasikan kemudian diolah secara deskriptif dalam bentuk prosentase untuk mengetahui apa saja penyakit akibat kerja yang berhubungan dengan ergonomi akibat kerja pada karyawan PG KREMBOONG. Untuk mengetahui gangguan kesehatan tersebut apakah bener - benar disebabkan karena kerja atau tidak diuji dengan uji Chi Square.

\section{HASIL DAN PEMBAHASAN}

Dalam penelitian ini diperoleh sampel sebanyak 60 karyawan yang memenuhi karakteristik sampel. Selanjutnya data yang diperoleh dan terkumpul ditabulasi, kemudian hasilnya disajikan dalam bentuk tabel.

\section{Tabel 1. Karakteristik Responden berdasarkan Faktor-faktor Ergonomi Kerja (dalam persen)}


Tabel 2. Karakteristik Responden berdasarkan Gangguan Kesehatan Akibat Kerja (dalam persen)

\begin{tabular}{ccccc}
\hline $\mathrm{N}$ & Variabel & $\begin{array}{c}\text { Bagian } \\
\text { Instalasi } \\
(\%)\end{array}$ & $\begin{array}{c}\text { Bagian } \\
\text { AKU }(\%)\end{array}$ & $\begin{array}{c}\text { Bagian } \\
\text { Tanaman } \\
(\%)\end{array}$ \\
\hline $1 \quad$ & Penyakit sebelum kerja & & & \\
& Mempunyai & 0 & 13 & 20 \\
& Tidak mempunyai & 100 & 87 & 80 \\
2. Penyakit setelah kerja & & & \\
& Nyeri pinggang & 37 & 0 & 56 \\
& Nyeri lutut & 24 & 71 & 0 \\
& Pusing & 0 & 0 & 11 \\
Batuk & 18 & 0 & 0 \\
Kram & 13 & 0 & 22 \\
Capek & 8 & 29 & 11 \\
\hline
\end{tabular}

Tabel 3. Karakteristik Responden berdasarkan Usaha Mengatasi Gangguan Kesehatan (dalam persen)

\begin{tabular}{clccc}
\hline $\begin{array}{c}\mathrm{N} \\
\mathrm{O}\end{array}$ & Variabel & $\begin{array}{c}\text { Bagian } \\
\text { Instalasi } \\
(\%)\end{array}$ & $\begin{array}{c}\text { Bagian } \\
\text { AKU }(\%)\end{array}$ & $\begin{array}{c}\text { Bagian } \\
\text { Tanaman } \\
(\%)\end{array}$ \\
\hline 1 & Mantri poliklinik & 96 & 100 & 80 \\
2 & Dokter poliklinik & 2 & 0 & 10 \\
3 & Puskesmas & 0 & 0 & 0 \\
4 & Dokter praktek & 2 & 0 & 0 \\
5 & Dokter spesialis & 0 & 0 & 0 \\
6 & Rumah sakit & 0 & 0 & 10 \\
7 & Lain-lain & 0 & 0 & 0 \\
\hline
\end{tabular}

Tabel 4. Hasil Analisis Data

\begin{tabular}{lccc}
\hline & $\begin{array}{l}\text { Nilai } \\
\text { Hitung }\end{array}$ & $\begin{array}{l}\text { Nilai } \\
\text { Tabel }\end{array}$ & $\begin{array}{l}\text { Nilai Signifikansi } \\
(\mathrm{p})\end{array}$ \\
\hline $\begin{array}{l}\text { Uji Korelasi product moment } \\
\text { (R) }\end{array}$ & 0,608 & & \\
Chi square gangguan & & & \\
kesehatan & & & \\
$\quad$ Nyeri pinggang & 6,429 & 3,841 & 0,011 \\
$\quad$ Nyeri lutut & 3,958 & 3,841 & 0,047 \\
$\quad$ Pusing & 4,800 & 3,841 & 0,028 \\
\hline
\end{tabular}

Berdasarkan tabel 1 didapatkan bagian instalasi posisinya berdiri sebanyak $45 \%$ karena sesuai dengan proses produksi dimana posisi kerja tersebut sesuai dengan alat yang digunakan pada waktu proses produksi berlansung. Pada bagian AKU sebanyak 100\% dan tanaman sebanyak 60\% pada posisi duduk dikarenakan posisi tersebut sesuai dengan alat kerja yang digunakan seperti komputer, alat tulis, mesin ketik. Posisi kerja duduk terus menerus pada waktu yang lama dapat menyebabkan pekerjaan akan terasa membosankan, beban kerja juga akan meningkat sehingga kelelahan cepat muncul.
Menurut Onishi (1991) melaporkan bahwa kerja dengan posisi duduk terus menerus menyebabkan kontraksi otot menjadi statis dan the load pattern menjadi lebih kuat dibanding kontraksi dinamis. Pada pekerjaan yang dilakukan dengan posisi duduk, tempat duduk yang dipakai harus memungkinkan untuk melakukan perubahan posisi. Ukuran tempat duduk disesuaikan dengan dimensi ukuran antropometri pemakainya. Lutut membentuk sudut $90^{\circ}$ dengan telapak kaki bertumpu pada lantai atau injakan kaki (Pheasant, 1998). Jika landasan kerja terlalu rendah, tulang belakang akan membungkuk kedepan, dan jika terlalu tinggi 
bahu akan terangkat dari posisi rileks, sehingga menyebabkan bahu dan leher menjadi tidak nyaman. Sanders dan Mc Cormick (1987) memberikan pedoman untuk mengatur ketinggian landasan kerja pada posisi duduk seperti menyediakan meja yang dapat diatur turun dan naik (jika memungkinkan), landasan kerja harus memungkinkan lengan menggantung pada posisi rileks dari bahu, dengan lengan bawah mendekati posisi horisontal atau sedikit menurun (Sloping down slightly) dan ketinggian landasan kerja tidak memerlukan fleksi tulang belakang yang berlebih.

Pada tabel 1 juga menunjukkan lama posisi kerja 8 jam sebanyak 49\% pada bagian instalasi, 5 jam sebanyak 49\% pada bagian AKU, 5 jam dan 8 jam sebanyak 40\% pada bagian tanaman. Semakin lama posisi kerja yang tidak diimbangi dengan perubahan posisi seperti pada bagian instalasi tidak ada perubahan posisi sebanyak 71\%, 75\% pada bagian AKU, seimbang antara ada perubahan posisi dan tidak terjadi pada bagian tanaman. Lama posisi kerja yang diikuti dengan adanya perubahan posisi dapat mengurangi beban kerja sehingga kelelahan dapat dicegah bagi pekerja. Menurut Grandjen (1993) sebaiknya posisi kerja duduk-berdiri secara bergantian (perubahan posisi) untuk menghindari kejenuhan dan ketegangan otot - otot pada anggota tubuh yang statis serta mengubah sikap kerja yang monotoni menjadi lebih bervariasi.

Pada tabel 2 didapatkan bahwa atribut yang digunakan saat bekerja pada bagian instalasi berupa masker dikarenakan lingkungan kerja yang berdebu, hasil samping yang berupa ampas yang mengandung partikel-partikel debu, asap mesin yang mengepul, bau dari proses produksi. Pada bagian AKU dan tanaman menggunakan atribut berupa baju kerja sebanyak 100\% karena merupakan kewajiban karyawan dan termasuk tata tertib perusahaan.

Lingkungan kerja meliputi kebersihan, ventilasi, pencahayaan ruangan serta hubungan dengan atasan, sesama dan bawahan. Pada tabel 2 didapatkan bahwa dibagian instalasi lingkungan kerja di setiap bagian kebanyakan memilih sebagai lingkungan yang baik. Pada hasil pengamatan didapatkan pada bagian instalasi pencahayaan dan ventilasi ruangan yang sedikit agak tertutup ruangannya sehingga memungkinkan ventilasi tersebut kurang memadai. Pada bagian AKU dan tanaman pencahayaan didapatkan dari lampu yang tidak pernah dibersihkan dan kelihatan kotor sehingga dapat menurunkan intensitas pencahayaan. Ventilasi ruangan pada bagian AKU dan tanaman berasal dari jendela dan dibantu kipas angin yang berada diatap.

Gangguan kesehatan yang terdapat di pabrik gula ini adalah batuk pilek, hipertensi, gastritis, penyakit otot, diabetes melitus, ISPA, penyakit jantung, penyakit kulit, penyakit pada rongga mulut, dan KIA. Dari gangguan kesehatan tersebut yang berhubungan dengan ergonomi kerja adalah penyakit otot. Sedangkan pada hasil penelitian didapatkan gangguan kesehatan akibat kerja yang dapat dilihat pada tabel 2 yaitu nyeri pinggang, nyeri lutut, dan pusing. Gangguan kesehatan tersebut disebabkan oleh banyak faktor diantaranya adalah konstraksi otot yang berlebihan akibat pemberian beban kerja yang terlalu berat dengan durasi pembebanan yang panjang (Suma'mur, 1982; Grandjen, 1993). Sikap kerja yang tidak alamiah juga berpengaruh, lebih banyak disebabkan oleh adanya ketidaksesuaian antara dimensi alat dan stasiun kerja dengan ukuran tubuh pekerja. Hal ini didukung dengan hasil observasi cara kerja yang tidak ergonomi, misalnya pada bagian produksi yakni ketidaksesuaian tarikan tali yang tinggi untuk pekerja yang tinggi badannya rendah, sikap membungkuk juga terjadi untuk beberapa pekerja yang dibagian gudang, pada bagian tanaman yaitu ketidaksesuaian antara alat kerja dengan cara kerja alat tersebut yang tidak sesuai dengan postur tubuh pekerja Indonesia. Sikap ini memicu terjadinya low back pain (LBP) yang menyerang otot bagian pinggang (Tarwaka, 2004).

Selain itu, mikrolimat yang tidak sesuai dengan standar sehingga menyebabkan gangguan kesehatan akibat kerja. Di samping itu dapat dipengaruhi oleh penerangan di tempat kerja. Hal tersebut didukung dengan hasil pengamatan lingkungan kerja yang tidak ergonomi, salah satunya pada bagian komputer dan bagian pembayaran yakni penerangan lampu yang tidak pernah dibersihkan dan kelihatan sangat kotor yang dapat menurunkan intensitas penerangan dan menimbulkan kelelahan pada mata dan pada akhirnya pekerja mengeluh pusing. Menurut Grandjen (1993) penerangan yang tidak didesain dengan baik akan menimbulkan gangguan atau kelelahan penglihatan selama kerja yang dapat menimbulkan keluhan pegal didaerah mata dan sakit kepala disekitar mata.

Pada tabel 3 menunjukkan bahwa usaha karyawan untuk mengatasi keluhannya dengan cara ke mantri poliklinik sebanyak 96\%, pada bagian AKU 100\% ke mantri poliklinik dan pada bagian tanaman sebanyak $80 \%$ ke mantri poliklinik. Hal semacam ini disebabkan karena mantri poliklinik selalu ada di poliklinik setiap jam kerja sedangkan dokter Rumah Sakit berkunjung seminggu sekali dengan waktu yang terbatas. Konsep pelayanan kesehatan seperti ini masih menggunakan konsep non holistik yaitu mengutamakan upaya pengobatan. Pelayanan kesehatan seharusnya dilakukan secara holistik yaitu dengan pendekatan pelayanan kesehatan dokter keluarga dengan menggunakan berbagai modul yang sesuai dengan masalah kesehatan yang dihadapi oleh karyawan dan keluarga. Ada juga karyawan yang mengunjungi Rumah Sakit yaitu sebanyak 10\%. Dari hasil pengamatan diketahui bahwa pekerja yang mengunjungi Rumah Sakit hanya pekerja yang dirujuk oleh dokter poliklinik tetapi belum ada program kunjungan Rumah Sakit oleh pelaksana pelayanan kesehatan.

Fungsi kunjungan Rumah Sakit adalah untuk mendampingi pasien yang dirawat di Rumah Sakit dalam rangka melakukan koordinasi dengan tim dokter Rumah Sakit atau spesialis agar tindak lanjut pengelolaan kesehatan pada pasien tersebut menjadi lebih optimal. Dalam hal ini dapat dicegah terjadinya rehospitalisation, mengoptimalkan biaya kesehatan dan meningkatkan kesejahteraan karyawan.

Dari hasil analisa data yang menggunakan uji korelasi product moment, didapatkan bahwa ada hubungan yang signifikans antara ergonomi kerja terhadap gangguan kesehatan akibat kerja dengan nilai $\mathrm{R}=0,608$. Adapun dari gangguan kesehatan setelah kerja, nilai hitung dari gangguan kesehatan pada bagian instalasi yang berupa nyeri pinggang adalah 6,429 ,untuk nyeri lutut 5,833, untuk pusing 6,429 dimana nilai tabel adalah 3,841. Dimana nilai hitung $>$ nilai 
tabel dan $\mathrm{p}<0,05$ yang berarti signifikans. Berarti dapat dilihat dari analisa tersebut bahwa nilai hitung $>$ nilai tabel yang berarti gangguan kesehatan pada bagian instalasi disebabkan karena faktor ergonomi kerja.

Pada bagian AKU, gangguan kesehatan setelah kerja sebanyak 4 mengalami pusing. Nilai hitung 4,800 sedangkan nilai tabel 3,841. Dimana nilai hitung $>$ nilai tabel dan $\mathrm{p}<0,05$ yang berarti signifikans. Berarti gangguan kesehatan yang berupa pusing pada bagian AKU disebabkan karena faktor ergonomi kerja.

Pada bagian tanaman, gangguan kesehatan setelah kerja sebanyak 12 mengalami nyeri pinggang dengan nilai hitung 4,087; 16 mengalami nyeri lutut dengan nilai hitung 3,958. Nilai tabel dari data tersebut adalah 3,841. Jika nilai hitung $>$ nilai tabel dan $\mathrm{p}<0,05$ maka signifikans.berarti gangguan kesehatan tersebut disebabkan karena faktor ergonomi kerja.

Penelitian ini memiliki kelemahan pada proses penentuan sampel yang diteliti. Pada proses penentuan sampel ini, peneliti menggunakan kuesioner sebagai metode pengumpulan data untuk mendapatkan data karyawan yang sesuai dengan karakteristik sampel. Kelemahan yang terletak pada pengisian kuesioner oleh responden dapat berupa : a) jawaban yang diberikan bersifat subjektif; b) dengan adanya pertanyaan yang sama untuk responden yang heterogen, maka penafsiran pertanyaan akan berbeda-beda sesuai dengan latar belakang sosial, pendidikan, dan sebagainya dari responden ; c) kejujuran dalam pengisian kuesioner. Serta didukung oleh perbedaan pada bagian-bagian dari sampel penelitian.

\section{SIMPULAN}

Berdasarkan penelitian ini, terdapat hubungan antara ergonomi kerja terhadap timbulnya gangguan kesehatan akibat kerja, yang mana paling banyak adalah nyeri pinggang, nyeri lutut, dan pusing. Dari hasil pengamatan faktor ergonomi yang mempengaruhi timbulnya gangguan kesehatan berikutnya adalah perubahan posisi kerja yang sebagian besar tidak mengalami perubahan posisi meskipun terdapat waktu istirahat selama 60 menit tetapi hal tersebut masih dapat menyebabkan kelelahan dan menyebabkan gangguan kesehatan akibat kerja.

\section{DAFTAR PUSTAKA}

Anonymous. 2006. Konsep Kesehatan Kerja. Malang. UMM Malang. Hal 1-2

Anonymous. 2006. Strategi Penanggulangan Penyakit Akibat Kerja. Malang.UMM Malang. Hal 1-3

Anonymous. 2005. Kematian Akibat Kerja Meningkat Di Dunia. http://www.media indonesia online.com. Diakses 7 Maret 2007.

Anonymous. 2007. Keselamatan Dan Kesehatan Kerja. http://www.pikiranrakyat.com. Diakses 9 April 2007.

Arikunto, Suharsini. 2006. Prosedur Penelitian. Rineka Cipta. Jakarta.

Arya, Wisnu, dkk. 1997. Aspek Keselamatan Kerja pada Pemakaian Komputer. http://www. elektroonlineand Indosatnet.co.id. Diakses 6 Maret 2007.
Juanita, Vivi. 2007. Kerja Sehat Membawa Berkat. http:// www.mediaindo.co.id. Diakses 9 Maret 2007.

Notoadmodjo, Soekidjo. 2002. Dasar - dasar Metodologi Penelitian Klinis. Bina Rupa Aksara. Jakarta.

Peraturan Menteri RI. 2007. Peraturan Menteri Tenaga Kerja Nomor PER01/MEN/1998. http:// www.nakertrans.go.id/perundangan / p / pp0_1_1998.php. Diakses 9 April 2007.

Pusat kesehatan kerja. 2007. Kecelakaan di Industri. http:/ /www.depkes.go.id. Diakses 9 April 2007.

Pusat kesehatan kerja. 2007. Prinsip Dasar Kesehatan Kerja. http://www.depkes.go.id. Diakses 9 April 2007.

Suma'mur, 1996. Higiene Perusahaan dan Kesehatan Kerja. PT. Gunung Agung. Jakarta.

Tarwaka, Sudiajeng. Lilik. 2 004. Ergonomi Untuk Keselamatan, Kesehatan Kerja dan Produktivitas. Surakarta : UNIBA PRESS. Hal 6-10,34, 107-110, $117-$ 123, 145-149

Undang-undang RI. 2007. UNDANG-UNDANG RI TAHUN 1970 tentang KeselamatanKerja. http://www. Theceli. com/dokumen/produk/1970/1-1970.htm. Diakses 22 Maret 2007.

WHO, Suyono, Joko. 2006. Deteksi Dini Penyakit Akibat Kerja. Jakarta : EGC. Hal 36-40

Widowati, Retno. 2005. Kesehatan Kulit Indikator Kesehatan Kerja. http:/ /www.kompascybermedia.com Diakses 7 Maret 2007.

Wiratmawati, Andina. 2006. Profil kecelakaan kerja Dan Faktor Keselamatan Kerja. Tesis. Universitas Muhammadiyah Malang. 